\title{
Vitality structure of the endemic Oxytropis kungurensis Knjasev (Fabaceae) coenopopulation on the eastern shore of Lake Aushkul (Republic of Bashkortostan)
}

\author{
Gulnaz Galikeeva, Olga Elizaryeva, Albert Muldashev, Natalia Tyutyunova, and Natalia \\ Maslova* $^{*}$ \\ Ufa Institute of Biology. Ufa Federal Research Centre, RAS, 69, prospekt Oktyabrya, Ufa, 450054, \\ Russia
}

\begin{abstract}
Consideration is given to biometric indices and vitality structure of Oxytropis kungurensis Knjasev (Fabaceae), an endemic species of the South Urals and Central Cis-Ural Region, observed in 2015 and 2016 in the coenopopulation on the eastern shore of Lake Aushkul (Uchalinsky District, Republic of Bashkortostan, Russia). The paper reveals differences in plant biometrics and vitality according to the years of observation. Judging from 14 biometric indices out of 19 indices analyzed, middle-aged generative plants in 2015 surpass those in 2016. Indices that characterize the vitality structure are higher in 2015 . The vitality type of the coenopopulation varies from prospering to depressive. Variations in biometric and vitality indices are associated with changing weather conditions during the vegetation period. In 2015, there were optimal conditions for plants to grow and develop.
\end{abstract}

\section{Introduction}

Assessment of the vitality state is part of comprehensive research on ecological and biological features of rare plant species. Information about the vitality status of each particular plant provides opportunities for revealing the vitality structure of coenopopulations (CPs) and their total assessment based on the proportion of plants with different vitality [1]. The results of such investigations demonstrate the stability and dynamics of a population in general and also detect the ecotope.

\section{Materials and Methods}

\subsection{Research Subject and Aims}

The subject of the research is Oxytropis kungurensis Knjasev (Fabaceae), an endemic species of the South Urals and Central Cis-Ural Region. The species is included into the

\footnotetext{
* Corresponding author: maslovanv-ib-ufa@mail.ru
} 
Red Data Book of the Republic of Bashkortostan (group 2, i.e. decreasing in the population number) as well as into the Red Data Book of the Perm and Chelyabinsk Regions [2]. In Bashkortostan, the species is found in 15 sites in the Uchalinsky and Beloretsky Districts. This mesoxerophyte occupies rock outcrops and stony steppes composed of limestones and mafic rocks (basalts, etc.) as well as highland tundras (Mashak Ridge). All known CPs of the species are usually scanty, and their current status is unsatisfactory [2]. The study of such species with a small number of localities and individual plants is highly topical [3-4].

The aim of this work is to study biometric indices and the vitality structure of $O$. kungurensis CPs on the eastern shore of Lake Aushkul in the Uchalinsky District of Bashkortostan. The research was conducted in 2015 and 2016. The CP area is about 180 $\mathrm{m}^{2}$. The slope of south-western exposition is about $20^{\circ}$ steep. Chernozem-like soils are very stony and poorly developed or organogenic rubbly. Vegetation is of the stony steppe type with thin grasses (projective cover is 35-40\%). The dominant role is played by petrophytic species characteristic of Trans-Uralian and Siberian steppes. Grazing is not frequent. $O$. kungurensis plants grow primarily on steppe plots covered with moss (projective cover is $10-20 \%)$.

\subsection{Research Methods and Statistical Analysis}

Biometric indices were studied in middle-aged generative plants. The number of samples analyzed was 22 plants in 2015 and 29 plants in 2016. A comparison of mean indicator values by the years of observation was performed using the Student's t-test [5]. The research on the vitality structure was carried out using two methods. According to the Zlobin's method [1], the determinant traits were selected out of 19 morphometric characteristics on the results of factor analysis. A two-dimensional approach was used to group the plants according to their height and number rosette-forming shoots. The plants were classified into three groups: $a$ - high vitality level, $b$ - average vitality level and $c-$ low vitality level. The quality of the $\mathrm{CP}$ was assessed using the integral index $\mathrm{Q}=(a+b) / 2$ [1]. The vitality of the CP was also determined using the method of Ishbirdin et al. [6]. The vitality indices of the CP (IVC) was calculated using the weighted average method according to 19 morphometric traits, and the ratio $\mathrm{I}_{\mathrm{q}}=(a+b) / 2 c$ was determined. Data statistical processing [6] was carried out for software packages MS Excel 2003 and Statistica 6.0.

\section{Results and Discussion}

A comparison of mean values of the biometric indices performed using the Student's t-test according to the years of observation showed reliable differences on the basis of 14 indices (Table 1). In 2015 these parameters were in 1.2 to 2.4 times higher than in 2016 (1.5 times higher on the average). For indices number of vegetative shoots, leaf lamina width, number of leaflet pairs, lateral leaflet length and width reliable differences was not showed.

Interannual differences in the biometric indices of the O. kungurensis middle-aged generative plants were also recorded in the CP $1.5 \mathrm{~km}$ south-westwards of Lake Aushkul when comparing the data for 2014 and 2015 [7].

The vitality status of plants and their CP varies depending on the year of observation. The year 2015 saw a prospering CP represented by three dimensional groups of plants (Table 2). The dominant plants were those of group $b(0.41)$ and group $a(0.50)$. Here, the quality index was maximal (0.45). Indices IVC and $\mathrm{I}_{\mathrm{Q}}$ had high values as well. In 2016, the $\mathrm{CP}$ contained dominant plants with the low vitality status (group $c$ ) -0.66 . The portions of plants were 0.31 for the intermediate-status group and only 0.03 for the high-status group, respectively. Such conditions were responsible for the formation of a depressive CP. The 
quality of the CP was 2.6 times lower as compared to 2015. The values of IVC and $\mathrm{I}_{\mathrm{Q}}$ indices were also low. The values of the quality index (Q) and vitality index (IVC) are in agreement with each other.

Table 1. Biometric indices of Oxytropis kungurensis middle-aged generative plants in the coenopopulation on the eastern shore of Lake Aushkul

\begin{tabular}{|l|c|c|c|}
\hline Indices & 2015 & 2016 & t $_{\text {actual. }}$ \\
\hline Plant height, cm & $25.1 \pm 1.0$ & $20.3 \pm 0.9$ & 3.732 \\
\hline Rosette height, cm & $14.5 \pm 0.5$ & $10.3 \pm 0.5$ & 5.686 \\
\hline Rosette diameter, cm & $21.8 \pm 1.1$ & $13.2 \pm 0.7$ & 6.603 \\
\hline Caudex diameter, cm & $5.8 \pm 0.4$ & $4.0 \pm 0.2$ & 4.279 \\
\hline Number of inflorescences, pcs & $9.2 \pm 0.7$ & $6.1 \pm 0.5$ & 3.504 \\
\hline Number of flowers per inflorescence, pcs & $15.1 \pm 0.5$ & $12.6 \pm 0.5$ & 3.535 \\
\hline Number of flowers per plant, pcs & $138.2 \pm 12.2$ & $77.4 \pm 7.4$ & 4.268 \\
\hline Number shoots per rosette, pcs & $7.2 \pm 1.0$ & $4.8 \pm 0.4$ & 2.382 \\
\hline Number of vegetative-generative shoots, pcs & $6.0 \pm 0.6$ & $3.8 \pm 0.3$ & 3.278 \\
\hline Number of leaves per plant, pcs & $31.0 \pm 3.8$ & $12.8 \pm 0.9$ & 4.654 \\
\hline Number of leaves per floriferous shoot, pcs & $5.0 \pm 0.3$ & $3.3 \pm 0.2$ & 5.505 \\
\hline Petiole length, cm & $6.3 \pm 0.3$ & $4.6 \pm 0.3$ & 4.192 \\
\hline Leaf lamina length, cm & $7.9 \pm 0.4$ & $5.8 \pm 0.3$ & 4.231 \\
\hline Leaf length, cm & $14.3 \pm 0.6$ & $10.4 \pm 0.6$ & 4.561 \\
\hline
\end{tabular}

Variations in the vitality indices are associated with different meteorological indicators during the vegetal periods in 2015 and 2016, primarily with the total precipitation in May and June. Anthropogenic effects on the CP remained the same. Long-term phenological observations in the Ufa Botanical Garden suggest that blooming and mass vegetative propagation occur in May and June [8]. This is a crucial period in the plant growth and development. Analysis of meteorological data showed that in 2015 the vicinities of Lake Aushkul received $187.8 \%$ of the long-term average precipitation in May and $110.2 \%$ in June (Figure 1), whereas in 2016 these values did not exceed $52.2 \%$ in May and $53.6 \%$ in June [9-10]. In 2015, there were optimal conditions for plant growth and development. Over the vegetal period the total precipitation comprised $328.5 \mathrm{~mm}$ in $2015(87.8 \%$ of the norm) and $259.9 \mathrm{~mm}$ in 2016 (69.5\% of the norm). In 2015, average monthly air temperature in May and June exceeded the average monthly norm, which exerted a favourable effect on plant growth rates. In 2016, average monthly air temperature during the same period was consistent with the long-term average. In 2016, the vital status of the plants was also affected by weather conditions occurred in August and September 2015. August was cool (average monthly air temperature was by $2.5^{\circ} \mathrm{C}$ below the norm) and September was dry (precipitation was $38.1 \%$ of the norm). This is precisely the period when the inflorescence formation takes place in this species. In 2016, such indices as the number of flowers per inflorescence and the number of inflorescences, flowers and vegetative-generative shoots per plant were lower.

Table 2. Vitality indices of the Oxytropis kungurensis coenopopulation on the eastern shore of Lake Aushkul

\begin{tabular}{|c|c|c|c|c|c|c|c|}
\hline \multirow{2}{*}{$\begin{array}{c}\text { Year of } \\
\text { observation }\end{array}$} & \multicolumn{3}{|c|}{$\begin{array}{c}\text { Proportion of plants } \\
\text { according to vitality groups }\end{array}$} & \multicolumn{5}{|c|}{ Vitality indices of the CP } \\
\cline { 2 - 8 } \cline { 6 - 8 } & $c$ & $b$ & $a$ & & $\mathrm{I}_{\mathrm{Q}}$ & IVC & Vitality type \\
\hline 2015 & 0.09 & 0.41 & 0.50 & 0.45 & 5.00 & 1.19 & prospering \\
\hline
\end{tabular}




\begin{tabular}{|l|l|l|l|l|l|l|l|}
\hline 2016 & 0.66 & 0.31 & 0.03 & 0.17 & 0.26 & 0.86 & depressive \\
\hline
\end{tabular}

The influence of ecological factors on the vitality of plants and CPs is diagnosed and studied in many studies [11-14]. For example, we determined the dependence of the vitality of plants and populations of Oxytropis baschkirensis Knjasev from weather changes [15].

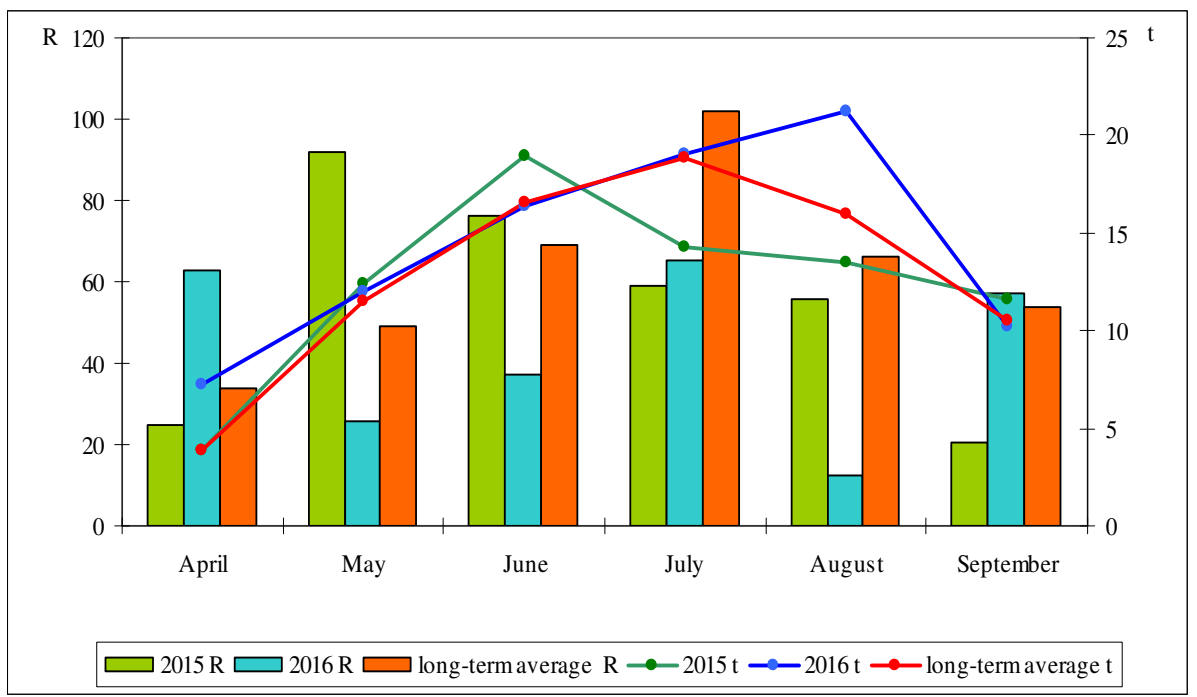

Fig. 1. Meteorological characteristics of the vegetation period in the area of investigation in 2015 and 2016. $X$-axis - months; Y-axis: right - air temperature, ${ }^{\circ} \mathrm{C} \mathrm{(t)}$; left-precipitation, $\mathrm{mm}$ (R).

Thus, biometric indices of $O$. kungurensis tend to vary depending on the year of observation. These variations affect the proportion of plants with different vitality status and eventually change the vitality type of the population.

\section{References}

1. Yu.A. Zlobin, Principles and methods study of plant coenotic populations (Educ. Kazan Univ., Kazan, 1989)

2. Red Data Book of the Republic of Bashkortostan, 1 (MediaPrint, Ufa, 2011)

3. P.L. Gorchakovsky, V.N. Zueva, Rus. J. Ecol. 3 (1984)

4. T.J. Walisch, G. Colling, M. Bodenseh, D. Matthies, Ann. Botan. 115, 7 (2015) doi:10.1093/aob/mcv040

5. G.N. Zaytsev, Mathematical analysis of biological data (Nauka, Moscow, 1991)

6. A.R. Ishbirdin, M.M. Ishmuratova, T.V. Zhirnova, Bull. N. Novgorod Univ. of N.I. Lobachevsky, Ser. Biol. 1, 9 (2005)

7. G.M. Galikeeva, N.V. Maslova, Bull. Ufa SC RAS 4, 1 (2015)

8. N.V. Maslova, O.A. Elizaryeva, G.M. Galikeeva, N.M. Tyutyunova, IOP Conf. Series: EES 107, 012086 (2017) doi:10.1088/1755-1315/107/1/012086

9. http://www.pogodaiklimat.ru/ (2018)

10. https://ru.climate-data.org/location/1843/ (2018)

11. R. Graper, Rhodora 82, 829 (1980) 
12. O. Solbrig, Evolution 35, 6 (1981)

13. M. Begon, M. Mortimer. Population ecology. A unified study of animals and plants (Blackwell Sci. Publ., Oxford, 1986)

14. J.D. Thompson., A.J. Gray, T. McNeilly, Acta Oecol. 11, 5 (1990)

15. N.V. Maslova, A.A. Muldashev, O.A. Elizaryeva, A.Kh. Galeeva, D.N. Kuvatova, Modern Probl. of Sc. and Educ. 3 (2015) 